\title{
Atendimentos Psicológicos Breves em Instituições Públicas de Saúde: Contribuições do Existencialismo Sartriano
}

\author{
Franciele Cabral Leão-Machado ${ }^{1}$ \\ Marina Menegueti Vaccaro ${ }^{1}$ \\ ${ }^{1}$ Universidade Estadual de Maringá, Maringá, PR, Brasil. $\quad$ IUniversidade Estadual de Maringá, Maringá, PR, Brasil. \\ Sylvia Mara Pires de Freitas ${ }^{1}$ \\ ${ }^{1}$ Universidade Estadual de Maringá, Maringá, PR, Brasil.
}

\begin{abstract}
Resumo: A inserção de psicólogos/as nas instituições de saúde, tais como hospitais e Unidades Básicas de Saúde (UBS), ocorreu em um contexto histórico-político-econômico específico e, desta forma, esteve voltada a atender às demandas do sistema de produção vigente. Esse processo exigiu dos profissionais algumas readequações de práticas clínicas tradicionais e utilização de outras modalidades de intervenções, como a psicoterapia breve e o plantão psicológico. Frente a isso, objetivamos expor as contribuições do existencialismo sartriano para a prática de atendimentos psicológicos de curta duração em instituições públicas de saúde, buscando mostrar que a proposta da psicanálise existencial realizada por Sartre e a utilização do método progressivo-regressivo proposto pelo autor não são restritas ao campo e à prática da psicoterapia tradicional. Por permitirem a compreensão da realidade humana em sua riqueza, dinamicidade e historicidade, podem contribuir sobremaneira para a realização de atendimentos psicológicos breves em instituições públicas de saúde, onde se pode encontrar uma ampla variedade de demandas e grande diversidade de queixas. Enfatiza-se ainda as contribuições do existencialismo sartriano para o contexto da saúde pública como um todo, na medida em que reforça valores defendidos por importantes políticas de saúde; desconstrói visões mecanicistas e biologizantes, ainda hoje tão presentes nos contextos institucionais de saúde; e auxilia a fortalecer uma visão ampliada da saúde, importante para a construção de práticas mais humanizadas e para uma maior responsabilização do sujeito no desenvolvimento de estratégias pessoais e coletivas de enfrentamento das dificuldades relacionadas aos processos de saúde/doença.
\end{abstract}

Palavras-chave: Atendimentos Breves, Saúde Pública, Existencialismo, Jean-Paul Sartre.

\section{Brief Psychological Therapy Sessions in Public Health Institutions: Contributions of the Sartrean Existentialism}

\begin{abstract}
Having occurred within a specific historical, political, and economic context, the introduction of Psychologists in health institutions such as hospitals and Basic Health Units (BHUs) sought to meet the demands of the current production system. With this insertion, traditional clinical practices had to be readapted and other intervention modes employed, such as brief psychotherapy sessions and psychological on-call shifts. Recent studies indicate the contributions of Sartrean Existentialism for brief psychological care offered in public health institutions, showing that Sartre's Existential Psychoanalysis and the Progressive-Regression Method are not limited to the field and practice of traditional psychotherapy. For understanding human concreteness in all its richness, dynamicity, and historicity, these practices contribute to the performance of brief psychological care sessions in public health institutions, where they meet a great variety of demands and a wide diversity of complaints. Besides psychological care, this study also emphasizes the contributions of Sartrean existentialism to the context of public health
\end{abstract}


as a whole, given that it reinforces values defended by important health policies; deconstructs mechanistic and biologizing views still rather prevalent within institutional health contexts; and helps to strengthen a broader perspective of health - important for the development of more humanized practices and for a greater accountability of the subject in developing personal and collective strategies to face difficulties related to the health/disease processes.

Keywords: Short Care Sessions, Public Health, Existentialism, Jean-Paul Sartre.

\title{
Atención Psicológica Breve en Instituciones Públicas Sanitarias: Contribuciones del Existencialismo Sartriano
}

\begin{abstract}
Resumen: La inserción de psicólogos/as en las instituciones sanitarias, tales como hospitales y Unidades Básicas de Salud (UBS), ocurrió en un contexto histórico-político-económico determinado para atender las demandas del sistema de producción vigente. La introducción de los profesionales en esos contextos exigió readecuaciones de prácticas clínicas tradicionales y utilización de otras modalidades de intervenciones como la psicoterapia breve y la guardia psicológica. Ante lo anterior, en este texto pretendemos exponer las contribuciones del existencialismo sartriano a la práctica de atención psicológica de corta duración en instituciones públicas sanitarias con el fin de evidenciar que la propuesta del psicoanálisis existencial realizada por Sartre y su método progresivo-regresivo no son restrictos al campo y a la práctica psicoterápica tradicional y, al posibilitar la comprensión de la realidad humana en su riqueza, dinamicidad e historicidad, pueden contribuir inmensamente con la realización de atención psicológica breve en instituciones públicas de salud, donde se encuentra una amplia variedad de demandas y diversidad de quejas. También se enfatizan las contribuciones del existencialismo sartriano al contexto de la salud pública en general, ya que refuerza los valores defendidos por importantes políticas de salud; deconstruye puntos de vista mecanicistas y biologizantes, todavía presentes en contextos institucionales de salud en la actualidad; y ayuda a fortalecer una visión más amplia de la salud, importante para la construcción de prácticas más humanizadas y para una mayor responsabilidad del tema en el desarrollo de estrategias de afrontamiento personales y colectivas, para enfrentar las dificultades relacionadas con los procesos de salud/enfermedad.
\end{abstract}

Palabras clave: Atención Breve, Salud Pública, Existencialismo, Jean-Paul Sartre.

\section{Introdução}

As reflexões aqui realizadas surgiram da prática das autoras como psicólogas e supervisoras de estágios em instituições de saúde, tais como hospitais e Unidades Básicas de Saúde (UBS). Isso porque os/ as alunos/as, já tendo estudado a base psicanalítica presente no surgimento das psicoterapias breves e estando cientes da afinidade que as supervisoras tinham com a abordagem existencial sartriana, no início do ano letivo, as questionaram sobre a possibilidade de sua utilização para a realização de atendimentos psicológicos de curta duração - psicoterapia breve, plantão psicológico etc. - em instituições de saúde.
Como forma de responder a esta inquietação frequente entre eles/as, este artigo buscará discorrer sobre as contribuições do existencialismo sartriano para a realização de atendimentos psicológicos de curta duração em instituições públicas de saúde.

Cabe mencionar, logo de início, que não temos a pretensão de elaborar uma sistematização que esgote o tema, mas sim de trazer reflexões que possam contribuir para a prática de profissionais atuantes em instituições públicas de saúde e, principalmente, para aqueles/as que buscam desenvolver suas práticas tendo como norte a perspectiva existencial sartriana. A relevância deste artigo está assentada no fato de que existem poucas publicações que discorrem espe- 
cificamente sobre as contribuições desta perspectiva para a realização de atendimentos psicológicos de curta duração em instituições públicas de saúde.

Para que o objetivo aqui proposto possa se cumprir, consideramos importante contextualizar a inserção dos/as psicólogos/as nas instituições públicas de saúde e as práticas mais comumente utilizadas pelos profissionais da área neste contexto, ainda que estejamos cientes de que a atuação na saúde pública de forma alguma deva se restringir à utilização das práticas que serão aqui abordadas. Em seguida, discorreremos sobre as contribuições do existencialismo sartriano para a psicologia clínica e para a realização de atendimentos psicológicos de curta duração no contexto das instituições públicas de saúde.

No decorrer de sua obra, o filósofo francês Jean-Paul Sartre (1905-1980) desenvolveu não só uma teoria, mas também uma metodologia para a compreensão da realidade humana a partir de uma concepção histórico-dialética, em que o sujeito só pode ser compreendido levando em consideração sua história individual e coletiva - e a relação que estabelece com o campo da materialidade. Além disso, o existencialismo sartriano "considera, ainda, o homem como aquele que se move para o futuro e que o faz em direção àquilo que ainda não é e que ainda pode realizar" (Pretto, Langaro, \& Santos, 2009, p. 398); portanto, Sartre compreende o homem a partir da dialética do que ele é e de suas possibilidades - do que ainda não é, ou seja, o vê como um vir-a-ser constante que, ao fazer-se em direção ao futuro, o faz superando seu passado.

Cremos que esta concepção de homem presente no existencialismo sartriano e os métodos utilizados por Sartre, que permitem a compreensão da complexidade da constituição do sujeito e da história, podem contribuir sobremaneira para a realização de atendimentos psicológicos em instituições públicas de saúde, onde se pode encontrar uma ampla variedade de demandas e grande diversidade de queixas.

\section{Inserção e práticas dos/as psicólogos/as em instituições públicas de saúde}

Sabe-se que o reconhecimento da psicologia como ramo de atuação profissional é algo recente, que aconteceu com a promulgação da Lei Federal no 4.119 (1962), dois anos antes do Golpe Militar de 1964 que instaurou um regime de ditadura militar no Brasil. Com a regulamentação da profissão, o/a psicólogo/a passou a atuar basicamente nas áreas clínica, escolar, indus- trial e de magistério. Naquele momento, as principais atividades realizadas por este/a profissional eram: avaliação psicológica, recrutamento/seleção profissional e orientação psicopedagógica (Scarparo \& Guareschi, 2007). Os/as psicólogos/as também aderiram a outras atividades que, até então, eram exclusivas dos/as médicos/as, como estudos de caso, perícias e psicoterapia (Dimenstein, 1998). Segundo Scarparo e Guareschi (2007, p. 100) "tratava-se de um período no qual o exercício da psicologia, em expressiva escala, se adequava às necessidades políticas e econômicas do governo militar ditatorial vigente".

No campo da saúde, as principais atividades dos/ as psicólogos/as se delimitavam a dois contextos: a prática do consultório particular, destinada às classes mais abastadas, e as atividades exercidas em ambulatórios e hospitais, cujo modelo de atuação estava subordinado à psiquiatria sob o enfoque de internação e medicação (Spink, 2011).

Não é difícil perceber, contudo, que atualmente tais áreas e atividades não representam mais a atuação dos/as psicólogos/as, que desde o final da década de 1970 teve uma ampliação significativa. Isso porque a sociedade e o sujeito contemporâneo têm demandado novas formas de inserção do/a psicólogo/a em novos espaços, como no campo da saúde pública, que absorveu grande parcela destes/as profissionais.

Dimenstein (1998), em seu artigo intitulado "O psicólogo nas Unidades Básicas de Saúde: Desafios para a formação e atuação profissionais", demonstra que a entrada dos/as psicólogos/as no âmbito das instituições públicas de saúde não se deu em um vazio social, mas em um contexto histórico-político-econômico determinado, que propiciou uma supervalorização cultural da profissão e a consolidação da ideia de que a atividade dos/das psicólogos/as era essencial para a sociedade.

Neste sentido, a autora destaca quatro fatores que contribuíram para a inserção do/a psicólogo/a no campo da saúde pública: a) o contexto das políticas públicas de saúde do final dos anos 1970 e da década de 1980, no que se refere à política de recursos humanos; b) a crise econômica e social no Brasil na década de 1980 e a retração do mercado dos atendimentos privados; c) os movimentos da categoria na tentativa de redefinição da função do/a psicólogo/a na sociedade; e d) difusão da psicanálise e psicologização da sociedade (Dimenstein, 1998).

No que diz respeito ao contexto das políticas públicas de saúde do final dos anos 1970 e da década de 1980, 
Dimenstein (1998) aponta que, durante este período, ocorreram diversos movimentos, programas e eventos com propostas de mudanças para o sistema vigente de assistência à saúde. Até então, esse sistema era baseado no modelo médico assistencial privatista, que privilegiava a prática médica curativa, individual e assistencialista em detrimento da saúde pública e, por isso, acabava por ser um sistema insatisfatório, oneroso e de baixa qualidade (Dimenstein, 1998).

As mudanças ocorridas nas políticas de saúde decorrentes destes movimentos, programas e eventos e das necessidades da sociedade de maneira geral contribuíram para a abertura do campo para outros/as profissionais da saúde, entre os quais, o/a psicólogo/a. Isso porque passou-se a enfatizar a importância da formação de equipes multidisciplinares para a reforma e organização dos serviços de saúde.

Gonçalves, Farinha e Goto (2016) destacam também o papel da Constituição de 1988 na reorganização do modelo de atenção à saúde, que passou a ser vista como um direito de cidadania e recurso que apoia o desenvolvimento individual e coletivo. Essa reorganização, segundo os autores, deu origem a várias estratégias e programas de intervenção, tal como a Estratégia Saúde da Família, que tem como objetivo garantir a promoção da saúde por meio de um atendimento acessível a todos, de forma contínua, integral e de qualidade.

Outro fator de grande relevância para o aumento do número de profissionais nas instituições públicas de saúde foi a crise econômica e social vivenciada no Brasil na década de 1980, que limitou o mercado dos atendimentos psicológicos privados, uma vez que a população e, principalmente, a classe média precisou cortar os gastos com os serviços psicológicos. Assim, os serviços públicos de psicologia passaram a ser atrativos tanto para a população que não tinha mais condições para arcar com os atendimentos psicológicos privados quanto para os/as profissionais, que encontravam nestes serviços certa estabilidade profissional devido à remuneração fixa e garantida que recebiam (Carvalho \& Yamamoto, 2002; Dimenstein, 1998; Pires \& Braga, 2009; Poubel, 2014).

Paralelamente, vários trabalhos foram realizados também na década de 1980 com o objetivo de redefinir a função do/a psicólogo/a na sociedade por meio da adoção de práticas mais condizentes e comprometidas com a realidade social do país, visto que a psicologia vinha sendo alvo de inúmeras críticas pelo fato de o trabalho clínico do/a psicólogo/a não apresentar grande relevância social. Assim,

os hospitais, os ambulatórios, postos e centros de saúde foram configurando-se como lugares privilegiados para a construção de novas práticas pelo psicólogo e como oportunidade de resgate de um certo prestígio social que vinha sendo perdido gradativamente com o passar dos anos (Dimenstein, 1998, pp. 67-68).

Por fim, Dimenstein (1998) destaca que a difusão da psicanálise no Brasil, decorrente da necessidade social de orientação das pessoas afetadas pela modernização acelerada experimentada pela sociedade brasileira na década de 1950, produziu uma cultura psicológica que contribuiu para o aumento da oferta de serviços de psicologia e para a expansão do campo e mercado de trabalho do/a psicólogo/a.

Spink (2011) ressalta que a inserção dos/as psicólogos/as na saúde pública foi complicada devido à resistência dos/as demais profissionais que compunham as equipes multiprofissionais e pela carência de embasamento teórico-prático para este novo campo de atuação. A autora destaca que a inexistência de conteúdos de saúde pública na graduação, o enfoque na atuação clínica na saúde mental, a compreensão do indivíduo desvinculado do contexto social e a hegemonia do modelo médico compartilhado pelos/ as profissionais se constituíram como empecilhos para a atuação dos/as psicólogos/as.

Concomitantemente ao incremento das políticas de saúde pública e à ampliação de seu alcance, os/as psicólogos/as também estavam em plena descoberta de seu novo campo de atuação. Devido à formação predominantemente clínica dos/as profissionais, a transposição deste modelo para a saúde pública gerou impasses e consequentes críticas à inadequação a este novo contexto.

Schneider (2002) menciona que, por vezes, a psicologia clínica não possui definições precisas e é compreendida a partir de seu local de realização (consultório particular e prática individual), de sua área de atuação (saúde versus escolar ou organizacional), ou mesmo enquanto campo de conhecimento, distanciado, por exemplo, da psicologia social. Como consequência, os saberes e fazeres psicológicos acabam compartimentalizados, ou seja, tornam-se especialidades cujas idiossincrasias desprezam o enredamento 
que há na relação indissociável entre o indivíduo e o campo sociomaterial.

Consideramos imprescindível mencionar os questionamentos dirigidos à psicologia clínica, que dizem respeito: a) ao fato de que esta foi formulada a partir do modelo médico com a finalidade de atender as classes sociais privilegiadas; b) a sua concepção individualista, a-histórica e associal oriunda da psiquiatria clínica; c) à herança do modelo empírico de saúde mental que busca classificações entre normal/anormal; d) à influência da medicina higienista, cuja finalidade é a de ajustamento de indivíduos; e e) à transposição deste modelo de forma generalista nos diversos campos de atuação dos/as psicólogos/as (Schneider, 2002).

Schneider (2002) aponta que tais questionamentos deram origem a diversas conquistas, como a luta política no interior da categoria, que buscou a melhoria da formação do/a psicólogo/a e de discussões permanentes a respeito das contribuições da psicologia para a sociedade. No entanto, ressalta que as críticas ao modelo clínico e à psicoterapia acarretaram uma negação apriorística desta prática, impossibilitando a superação de seus impasses. A autora nos alerta sobre críticas equivocadas, que não consideram que, quando ocorrem superações de condições históricas, as circunstâncias anteriores não são aniquiladas, muitas delas são preservadas e convivem com as novas. Este é o caso do modelo clínico tradicional de psicoterapia, que até hoje é aplicado, inclusive no campo da saúde pública. Negá-los, por conseguinte, é contribuir para manutenção de seus obstáculos a uma formação politizada e crítica.

Não é aconselhável considerar que a psicoterapia, por se direcionar ao indivíduo, perde sua capacidade de contribuir com a saúde mental da população. O problema parece residir quando o foco da psicoterapia é direcionado ao indivíduo como uma singularidade que se constitui enquanto sujeito a parte do contexto sociomaterial.

A partir da entrada dos/as psicólogos/as no campo da saúde pública, houve a necessidade de se repensar a prática clínica neste contexto, bem como de se ampliar as formas de atuação para práticas coletivas, cuja finalidade era estender o acesso ao atendimento em saúde mental à população.

Além dos fatores mencionados anteriormente, não se pode deixar de citar duas importantes iniciativas que contribuíram para o estabelecimento de uma relação mais ampla entre saúde mental e atenção básica - que se constitui como um dos principais campos de atu- ação dos/as psicólogos/as na saúde pública - e para uma maior inserção do/a profissional da psicologia neste campo. Essas iniciativas são a Política Nacional de Humanização (PNH) (Brasil, 2008) e o apoio matricial, desde 2008 realizado pelas equipes do Núcleo de Apoio à Saúde da Família (Nasf) e cuja recomendação é a existência de pelo menos um profissional da saúde mental como parte da equipe multiprofissional. Tais iniciativas defendem a ideia de que se deve promover saúde "tendo em mente que o ser que busca atendimento na unidade é um ser biopsicossocial e que precisa ser compreendido em sua multidimensionalidade e complexidade, $o$ que exige um trabalho multidisciplinar" (Gonçalves et al., 2016, p. 226).

A PNH se configura como uma aposta do Ministério da Saúde na humanização e na transformação do processo de cuidado em saúde por meio de trocas solidárias em redes multiprofissionais e interdisciplinares, envolvendo gestores, profissionais e usuários. Para isso, foram instituídos no SUS dez programas que visam operacionalizar essas mudanças, entre os quais destacamos a Clínica Ampliada e Compartilhada e Atenção Básica.

A proposta da clínica ampliada é compartilhar entre a equipe multiprofissional o diagnóstico e projetos terapêuticos, oferecendo ao/à usuário/a uma compreensão ampliada sobre o processo de saúde-doença. Essa estratégia visa superar a hierarquização das instâncias biomédica, psicológica e social e aumentar as práticas coletivas, a comunicação entre a equipe multiprofissional e entre as equipes da rede (Brasil, 2009).

Já a Atenção Básica é apontada como um dos principais caminhos que promovem a humanização, pois o acompanhamento por uma equipe multiprofissional em um território específico e ao longo do tempo contribui com a criação de vínculo entre profissionais e usuários/as. Promovidas pela Estratégia de Saúde da Família, as práticas do cuidado em saúde na Atenção Básica podem ocorrer nos atendimentos da UBS, em visitas domiciliares, na realização de grupos, oficinas de planejamento, reunião do Conselho Local de Saúde, roda de conversa temática etc. (Brasil, 2008).

Devemos considerar que o incentivo às práticas coletivas advindos das políticas públicas transformou a atuação dos/as psicólogos/as e ampliou o campo de produção de conhecimento da psicologia. No entanto, conforme pesquisa realizada por Archanjo e Schraiber (2012) acerca da atuação de psicólogos/as em algumas 
UBS na cidade de São Paulo, há uma considerável diferença entre a expectativa do profissional em atuar com ações preventivas, educativas e de promoção à saúde mental realizadas com a comunidade e a forma como é possível atuar, uma vez que as UBS também foram projetadas visando ações "curativas" clínico-sanitárias, que preveem o diagnóstico, tratamento e acompanhamento do usuário.

Por isso, há uma constante tensão entre curativo e preventivo. Apesar de se reconhecer que a UBS é espaço para se realizar os dois tipos de intervenção, há sempre a reclamação de que a demanda de doença é muito maior do que a de saúde. É válido dizer que ações preventivas e de promoção foram colocadas por algumas entrevistadas como não sendo valorizadas ea exigência é para que se atenda o maior número de pessoas possível, o que causa desconforto no profissional, que precisa lidar com exigências políticas e com as de seus órgãos fiscalizadores de conduta, que nem sempre encontram um consenso (Archanjo \& Schraiber, 2012, p. 358).

Esta cobrança de realização de atendimentos para um maior número de pessoas a que o/a psicólogo/a vem sendo submetido/a exigiu do/a profissional a criação e utilização de outras modalidades de intervenções, tais como a psicoterapia breve e o plantão psicológico. Essas modalidades são diferentes daquelas características da psicologia clínica tradicional - de orientação predominantemente psicanalítica, que não prevê aconselhamento, demanda setting terapêutico adequado aos padrões da abordagem, postura estrita dos/as profissionais e encontros frequentes por longos períodos.

A psicoterapia breve, segundo Fiorini (2004), tem suas raízes no período de guerra, ou seja, em uma época em que havia uma grande demanda para atendimento psicológico, e consiste em um processo terapêutico realizado dentro de um tempo limitado que se adapta às condições e demandas institucionais. Já o plantão psicológico surgiu para atender à grande demanda de sofrimento psicológico, em seu caráter emergencial, decorrente da atual situação econômica, social, política e cultural em que se encontra a população brasileira menos favorecida - esta que, em sua maioria, não tem acesso a atendimento em consultórios particulares (Furigo et al., 2008). Tal modalidade de intervenção do/a psicólogo/a foi definida por Tassinari (2009, p. 176) como

um tipo de atendimento psicológico, que se completa em si mesmo, realizado em uma ou mais consultas sem duração pré-determinada [e sem a necessidade de agendamento prévio], objetivando receber qualquer pessoa no momento exato de sua necessidade para ajudá-la a compreender melhor sua emergência e, se necessário, encaminhá-la a outros serviços.

Esta ocupação de novos espaços de atuação e a utilização de novas modalidades de intervenção por parte dos/as psicólogos/as abre, segundo Vendruscolo (2015, p. 121), diversos questionamentos, a exemplo de: como deve ser a sua intervenção no contexto institucional na área da saúde? Há necessidade de se empregar técnicas específicas para diferentes momentos? Deve ser respaldada pelo modelo clínico, representado prioritariamente pela psicoterapia?

Respondendo a esses questionamentos pela perspectiva do existencialismo sartriano e considerando que essas modalidades de intervenção têm, hegemonicamente, uma forte base psicanalítica (Oliveira, 1999; Vendruscolo, 2015), acreditamos que a psicologia existencialista sartriana pode contribuir para a realização de atendimentos psicológicos de curta duração em instituições públicas de saúde. Vejamos a seguir sobre quais bases do existencialismo sartriano nos debruçamos para justificar a possibilidade de sua utilização nos contextos institucionais de saúde em que coexistem a necessidade de se fazer psicoterapia e a necessidade de que esta seja breve.

\section{Contribuições do existencialismo sartriano para a psicologia clínica}

Enquanto área de atuação do/a psicólogo/a, a psicologia clínica é definida pelo Conselho Federal de Psicologia ([CFP], 1992, p. 2) como: "atuação através de intervenções que visam reduzir o sofrimento do homem, levando em conta a complexidade do humano e sua subjetividade". A psicologia clínica, por tradição, é considerada como uma especialidade do modelo da medicina clínica, da psiquiatria e psicanálise. Além disso, resulta de outras influências dos contextos históricos e socioculturais de seu período de desenvolvimento, como a psicometria e a Segunda Guerra Mundial (Schneider, 2002).

Schneider (2002) afirma que uma definição da psicologia clínica é controversa, no entanto, a partir da consideração de seu histórico, pode ser delimitada enquanto: a) método, pois abarca avaliações e diagnósticos do contexto e da história pessoal dos sujeitos, 
visando o planejamento de intervenções preventivas, terapêuticas ou educativas; b) campo de atuação do psicólogo na área da saúde, pois objetiva a superação do sofrimento psíquico e; c) campo de produção de conhecimento, ao fundamentar pesquisas e elaboração de teorias a respeito da realidade psicossocial e dos sujeitos. Assim sendo, a área de estudo não se restringe à prática de consultório, pois não remete a uma disciplina elaborada para apenas um local de aplicação. Ao considerar que tal especialidade se traduz também como um lócus de produção de conhecimento, diversas teorias embasam sua prática, como a psicanálise, o behaviorismo, a gestalt etc.

A inserção de Sartre na psicologia clínica tem relação direta com o desenvolvimento da psicanálise. O filósofo estudou a teoria psicanalítica e sua prática clínica, reconhecendo sua contribuição às ciências humanas no que tange ao estudo das psicopatologias, à significação dos atos humanos e à consideração do contexto sociocultural; no entanto, contestou Freud por dotar o psíquico de estruturas e energias, e igualmente por considerar que os fenômenos podem ser inconscientes.

A psicanálise existencial é a apresentação de um método e uma proposta de Sartre para a compreensão da realidade humana, partindo da ideia de que o ser humano é liberdade em situação e considerando o recorte de seu contexto histórico e social. Tal compreensão visa não restringir os sujeitos aos determinismos históricos e, principalmente, recusa a ideia de que o ser humano é analisável e reduzido aos "dados primordiais" (desejos e tendências) (Sartre, 2011).

Contrariando muitos entendimentos que desconsideram a possibilidade de o sujeito ser livre porque há uma sociedade que o determina, Sartre, ao acentuar a importância da liberdade, quis nos informar que é o sujeito quem escolhe o que apreenderá do mundo e como agirá sobre ele conforme os limites e possibilidades do contexto em que se insere. Isto porque, diante de infinitas determinações sociais, o sujeito não conseguirá apreender a totalidade delas, e há a necessidade de escolher o que visará em determinado momento. A consciência de um fenômeno requer a negação (na dimensão ontológica) de outros; visar outro, por conseguinte, requer a nadificação do fenômeno anteriormente visado. A consciência, portanto, tanto apreende o mundo quanto se desvencilha dele num ato brusco, e isto só é possível por ela não ser substancializada, o que lhe confere a liberdade de afirmar e de negar o mundo.
No trecho de uma de suas principais obras, $O$ ser e o nada: Ensaio de ontologia fenomenológica, Sartre (2011) dedica-se à exposição da psicanálise existencial, que tem como princípio a concepção de homem como uma totalidade que não se faz por somas de partes, mas pela unidade sintética delas - tanto as mais simples, superficiais e cotidianas quanto as mais complexas e incomuns. Para chegar a essa unidade (sua totalidade), é necessário ter como ponto de partida a experiência da pessoa, haja vista ser pela experiência que o indivíduo significa o que visa e lhe dá um sentido. O sentido que dará a suas ações diante desta apreensão nos revela como busca suprir suas necessidades. À vista disto, a realidade humana se define pelos fins que a pessoa persegue. O projeto existencial, ou projeto original, portanto, trata-se de uma unidade pessoal, que é "Ser" e que deve ser entendido como um absoluto não substancial, como uma totalidade (identidade, Eu ou Selff, que é construída em curso.

Cabe ao/a psicólogo/a acompanhar o movimento da pessoa buscando compreender como esta age, projetando-se ao futuro para superar as condições objetivas passadas (movimento progressivo-regressivo) e comparar suas ações a fim de decifrar como se unificam (movimento analítico-sintético).

A infinitude de possibilidades de ser terá sua finitude significada pelas escolhas que cada pessoa faz de si, ao fazer-se na relação com o campo sociomaterial. É por esta razão que Sartre (2011) refuta análises que recorrem às possibilidades já determinadas para as ações humanas. Acrescentamos que uma investigação do projeto original bem conduzida se faz pela escuta fenomenológica e hermenêutica e, devido a isso, os projetos revelados pela psicanálise existencial só podem ser apreendidos a partir do ponto de vista da própria pessoa.

Sartre não reconhece algo antes da liberdade enquanto condição ontológica humana, como mencionado, tampouco pensa o ser humano subjugado à história - o ser que lhe falta é perseguido por meio do fluxo de uma historização perpétua, "por isso, ambas [a psicanálise empírica e a psicanálise existencial] consideram o homem no mundo e não aceitam a possibilidade de questionar o que um homem é sem levar em conta, antes de tudo, sua situação" (Sartre, 2011, p. 697).

Após apresentar a psicanálise existencial em $O$ Ser e o Nada (Sartre, 2011) como método de investigação da realidade humana, Sartre, por sua aproximação com o pensamento do jovem Marx e do marxista 
francês Henri Lefebvre, aprofunda a compreensão da constituição histórico-dialética do sujeito em duas obras publicadas em 1960, Questão de Método e Crítica da Razão Dialética, que auxiliam a situar o indivíduo na história (Vaccaro, 2014). A necessidade de compreender como o indivíduo se constrói como sujeito histórico sem perder sua singularidade remete a uma crise epistemológica dos métodos científicos e à demanda de superação entre as perspectivas objetivistas e subjetivistas.

$\mathrm{Na}$ dimensão antropológica, portanto, ser-em-situação nos informa que a escolha é condicionada pelos possíveis, tendo em conta que se considera os determinantes históricos que condicionam a pessoa a escolher entre o que lhe é viável, descontruindo, deste modo, a concepção de que ser livre, para Sartre, é poder escolher o que se quer.

O/a psicólogo/a que trabalha em instituições de saúde pública igualmente está inserido em um contexto que condiciona seu trabalho. Este contexto envolve, geralmente, a demanda de uma pessoa, família ou grupo que procura ajuda para reduzir seu sofrimento; no entanto, o trabalho do/a psicólogo/a é delimitado pela quantidade de sessões e pelo ambiente em que serão realizadas; de igual forma, a perspectiva pela qual apreenderá o sofrimento alheio é balizada pela abordagem teórico-metodológica com a qual se afina.

Outro aspecto condicionante da atuação do/a psicólogo/a é a relação com a pessoa que atende. Nascimento, Campos e Alt (2012) apontam que a clínica de inspiração sartriana ressalta a relação entre a dupla terapêutica como necessária para a construção de sentidos conjuntamente. Nesta relação, que se faz dialeticamente, não devem ser considerados somente os atos da pessoa atendida como manifestação de seu projeto, como apregoa Sartre (2011), mas igualmente os do/a psicólogo/a. Como os atos deste/a mediarão o usuário com seu projeto, o sentido da mediação deve ser tecido dialeticamente com o sentido atribuído a seu projeto.

Com a ampliação da compreensão de Sartre sobre o contexto sócio-histórico que o indivíduo se insere, o projeto original, por conseguinte, passa a ser visto como fruto das determinantes materiais, sociais e históricas em que se encontra, sendo o resultado das condições objetivas e da apropriação subjetiva de tais condições (Schneider, 2006).

Sartre (2002) aponta que, no interior do movimento dialético, o ser humano é condicionado pelos fatores objetivos de sua realidade "na medida mesma em que ele os condiciona" (p. 170). O método progressivo-regressivo do existencialismo diz respeito, portanto, à análise de como a conjuntura sócio-histórica condiciona os sujeitos, como eles a apreendem e, enquanto agentes históricos, co-constroem a realidade. $\mathrm{O}$ foco, portanto, será sempre no sujeito da ação, no sujeito em situação. $\mathrm{O}$ acontecimento atual, portanto, auxiliará a iluminar, concomitantemente, as condições ele está superando na relação dialética com as condições futuras que deseja construir.

Dessa forma, a filosofia sartriana considera a perspectiva histórico-dialética na compreensão da realidade humana: o sujeito nasce em uma circunstância específica que contém a história em si, o que igualmente the configura como um sujeito universal. Torna-se singular por meio de como se apropria do contexto universal e de como lida com este, considerando-se os seus possíveis.

Colocadas as contribuições do pensamento de Sartre para a compreensão da constituição do sujeito, cabe relacioná-las a um contexto de atuação do/a psicólogo/a que o limita, de certa forma, à duração dos atendimentos e que, a princípio, pode indicar restrições à utilização da abordagem existencialista.

\section{Contribuições do existencialismo sartriano para a realização de atendimentos psicológicos de curta duração}

Após termos abordado a inserção do/a psicólogo/a no contexto da saúde pública e discorrido sobre as contribuições do existencialismo sartriano para a psicologia clínica, buscaremos, a partir de agora, refletir acerca dos questionamentos colocados anteriormente sobre as possíveis contribuições da teoria e do método sartriano para a realização de atendimentos psicológicos em instituições públicas de saúde.

Podemos iniciar destacando a contribuição da própria visão de homem presente no existencialismo sartriano que coaduna com a visão de homem recomendada por importantes políticas de saúde, tal como a PNH. Isso porque, para a perspectiva existencial sartriana, o sujeito é concebido como corpo (objetividade) e consciência (subjetividade), não podendo ser reduzido a nenhuma destas dimensões, o que faz com que tanto sua dimensão biológica quanto a dimensão psicológica sejam levadas em consideração, uma vez que Sartre as considera indissociáveis. 
Além de ser considerado enquanto corpo e consciência, têm-se, ainda nesta perspectiva, um sujeito que é concebido como um ser concreto e relacional, na medida em que está tecido no mundo e, portanto, é constituído por este, ao mesmo tempo em que o constitui. Assim, percebe-se que o existencialismo traz a ideia de um homem que é produto e produtor do contexto no qual está inserido, como já mencionado.

Esta visão do homem como um ser psicofísico ou seja, como um ser que é "todo inteiro corpo e todo inteiro consciência” (Sartre, 2011, p. 388) - que está em constante relação, e se constituindo a partir dessas relações, quando levada ao contexto da saúde pública, contribui para o surgimento de uma concepção ampliada de saúde. Dessa forma, a saúde deixa de ser vista a partir de uma visão biologicista, passando a ser concebida como um fenômeno biopsicossocial que contempla o homem em sua totalidade existencial, considerando-se os enredamentos de suas relações.

Sendo assim, é possível dizer que, na perspectiva existencial sartriana, a pessoa que ali se apresenta e principalmente seu sofrimento e até mesmo seu adoecimento psíquico não serão considerados de maneira isolada, mas sim contextualizada, levando em consideração sua história de relações que pode ter contribuído para que se constituísse de determinada forma, inclusive seu histórico de relações de cuidados recebidos no contexto da saúde pública.

De acordo com Pretto et al. (2009, p. 399), "qualquer complicação psicológica diz respeito justamente ao movimento do homem no mundo; assim, ela será compreendida na medida em que seja possível conhecer a história do sujeito, suas relações e a inteligibilidade que ele atribuiu as ocorrências experienciadas psicofisicamente".

Esta concepção dialética presente no existencialismo sartriano, que entende o homem como produto e produtor, não permite que o consideremos como agente passivo e alheio a seu contexto de saúde-doença, na medida em que participa ativamente da construção deste contexto, não só numa perspectiva individual, mas também coletiva. Com isso, fica evidente que a perspectiva existencial contribui para reforçar valores que norteiam políticas de saúde, tais como autonomia, protagonismo e corresponsabilidade.

Além da visão de homem, o método sartriano também pode contribuir sobremaneira para a realização de atendimentos psicológicos, mesmo em contextos institucionais de saúde em que há necessidade de que tais atendimentos sejam realizados em curto período.

Em O ser e o nada: Ensaio de ontologia fenomenológica, Sartre (2011, p. 696) afirma que o princípio da psicanálise existencial

consiste na assertiva de que o homem é uma totalidade e não uma coleção; em consequência, ele se exprime inteiro na mais insignificante e mais superficial das condutas - em outras palavras: não há um só gosto, um só tique, um único gesto humano que não seja revelador (grifos do autor).

Esta ideia do homem como totalidade que se exprime inteira em todas as suas condutas, gostos e gestos nos leva a pensar que, até mesmo em um contexto que demanda a realização de atendimentos psicológicos de curta duração, há a possibilidade de elucidar unidades nas sínteses de suas ações. A queixa trazida no momento do atendimento não é entendida como um aspecto isolado da sua existência, mas como um fenômeno enredado com sua totalidade. Isso significa que, ao explorarmos a queixa junto à pessoa atendida, podemos não só ajudá-la a lidar com a situação-problema para que possa criar possibilidades de enfrentamento, mas também a ter uma maior compreensão de si, dos significados que dá às adversidades que irrompem em seu existir e dos sentidos que dá diante delas pelas suas ações.

Todavia, se pensarmos que o método da psicanálise existencial é comparativo, uma vez que, tal como aponta Sartre (2011), é pela comparação das condutas humanas que fazemos brotar a revelação única que todas exprimem de maneira diferente, não podemos descartar a possibilidade de que, em alguns casos, pelo contexto breve em que os atendimentos são realizados na saúde pública, não seja possível elucidar o projeto original do usuário dos serviços de saúde. Isso porque se pensarmos na prática do plantão psicológico, por exemplo, há a possibilidade de que o atendimento seja realizado em um ou dois encontros, o que tornaria inviável essa comparação das condutas, tal como foi proposto por Sartre (2011).

Por mais que a configuração do atendimento muitas vezes não permita a elucidação da escolha original, ele ainda pode ser um espaço valioso para a tematização do existir humano, levando em consideração as contradições que a pessoa atendida experiencia naquele momento específico e suas pos- 
sibilidades de superação dessas contradições, o que pode ser realizado recorrendo ao método progressivo-regressivo. Tal método permite compreender o que do campo sociomaterial confronta a liberdade da pessoa atendida e o que a medeia com essa situação que compromete seu ser sujeito. Ao identificar as contradições e mediações de sua situação, essas podem ser-lhe desveladas pelo/a psicólogo/a, contribuindo para que juntos/as possam decidir pelo melhor encaminhamento a ser dado ao caso.

\section{Considerações finais}

Com base no que foi exposto e buscando responder aos questionamentos sobre as possíveis contribuições da psicologia existencialista de base sartriana para a realização de atendimentos psicológicos de curta duração em instituições públicas de saúde, tem-se que tal perspectiva, pela visão de mundo que adota e pelos métodos que utiliza (fenomenológico, psicanálise existencial e progressivo-regressivo), pode contribuir sobremaneira de duas formas. A primeira é a apreensão do fenômeno, pelo/a psicólogo/a, de maneira cúmplice com a pessoa atendida, isenta de julgamentos num primeiro momento, mas o analisando compreensivamente; em segundo lugar, cita-se a elucidação de seu projeto de ser, ou mesmo, em condições de atendimento limitadas pelo tempo, o desvelar das contradições e mediações das condições em que a pessoa se insere.

Ademais, a abordagem existencialista sartriana pode não só auxiliar na realização de atendimentos psicológicos - mesmo os de curta duração -, mas também para reforçar valores defendidos por importantes políticas de saúde. Isso porque, tal como foi visto anteriormente, a compreensão do homem em sua totalidade existencial, ou seja, como corpo e consciência que está em constante relação com a realidade em que vive, construindo-a e sendo construído por ela, contribui com o projeto de desconstrução de visões mecanicistas e biologizantes, que ainda hoje se fazem presentes nos contextos institucionais de saúde. Como resultado, temos o fortalecimento de uma visão ampliada da saúde, tão importante para a construção de práticas mais humanizadas e para uma maior responsabilização do sujeito no desenvolvimento de estratégias pessoais e coletivas de enfrentamento das dificuldades relacionadas aos processos de saúde/doença (Pretto et al., 2009).
Além disso, ainda que sejamos contrárias à simples transposição das práticas clínicas tradicionais para o contexto institucional, defende-se que o método existencialista, por sua amplitude, não necessita de adaptações para ser utilizado em contextos institucionais, uma vez que permite a compreensão do homem enquanto ser genérico e particular e que, por isso, pode ser utilizado nos mais diversos contextos.

Neste sentido, concordamos com Vendruscolo (2015, p. 123) quando afirma que "acrescentar à expressão Atendimento Psicológico um complemento para designar o contexto em que ele é realizado ... caracteriza uma fragmentação do existir humano em diferentes situações", fragmentação esta que vai justamente na direção contrária ao que é defendido pelo existencialismo sartriano.

Assim, pode-se dizer que o existencialismo sartriano contribui para a realização de atendimentos psicológicos de curta duração em instituições de saúde a julgar por não se amparar em técnicas ou instrumentos prescritos para determinados contextos ou modalidades terapêuticas que, muitas vezes, levam ao empobrecimento e à desumanização do encontro entre o psicólogo e a pessoa por ele atendida. Seus métodos exigem que o/a psicólogo/a seja o próprio meio para a compreensão do humano, independentemente do contexto em que este se encontra, seja no consultório particular em uma psicoterapia de longa duração ou no contexto da saúde pública, submetido a atendimentos breves. Isto porque os métodos utilizados por esta abordagem implicam o/a psicólogo/a como produtor/a e produto da relação e do contexto da saúde pública; demandam, portanto, que este/a profissional tenha consciência, inclusive, das condições políticas e econômicas da época em que realiza seu trabalho, como a atual, em que observamos uma política governamental conservadora no Brasil, que visa o desmonte das políticas públicas e, por conseguinte, o incremento das práticas clínicas tradicionais da psicologia, fragilizando as que priorizam a promoção e prevenção da saúde.

À vista disto, na prática de atendimentos de curta duração, o existencialismo sartriano contribuirá para a compreensão das demandas como produtos e produtoras deste contexto e exigirá o comprometimento do/a psicólogo/a não somente com a prática clínica, mas com o engajamento ético-político no contexto da saúde pública. 


\section{Referências}

Archanjo, A. M., \& Schraiber, L. B. (2012). A atuação dos psicólogos em unidades básicas de saúde na cidade de São Paulo. Saúde e Sociedade, 21(2), 351363. https://doi.org/10.1590/S0104-12902012000200009

Brasil. (2008). Humaniza/SUS: Documento base para gestores e trabalhadores do SUS. 4a ed. Ministério da Saúde.

Brasil. (2009). Clínica ampliada e compartilhada. Ministério da Saúde.

Carvalho, D. B., \& Yamamoto, O. H. (2002). Psicologia e políticas públicas de saúde: Anotações para uma análise da experiência brasileira. Psicologia para a América Latina, 1, 112.

Conselho Federal de Psicologia. (1992). Atribuições profissionais do psicólogo no Brasil. https://site.cfp.org.br/ wp-content/uploads/2008/08/atr_prof_psicologo.pdf

Dimenstein, M. D. B. (1998). O psicólogo nas Unidades Básicas de Saúde: Desafios para a formação e atuação profissionais. Estudos de Psicologia, 3(1), 5381. https://doi.org/10.1590/S1413-294X1998000100004

Fiorini, H. (2004). Teorias e técnicas de psicoterapias. Martins Fontes.

Furigo, R. C. P. L, Sampedro, K. M., Zanelato, L. S., Foloni, R. F., Ballalai, R. C., \& Ormrod, T. (2008). Plantão psicológico: Uma prática que se consolida. Boletim de Psicologia, 58(129), 185192.

Gonçalves, L. O., Farinha, M. G., \& Goto, T. A. (2016). Plantão psicológico em Unidade Básica de Saúde: Atendimento em abordagem humanista-fenomenológica. Revista da Abordagem Gestáltica, 22(2), 225232.

Lei no 4.119, de 27 de agosto de 1962. (1962, 17 de dezembro). Parte vetada pelo Presidente da República e mantida pelo Congresso Nacional, do Projeto que se transformou na Lei no 4.119, de 27 de agosto de 1962 (que dispõe sobre os cursos de formação em Psicologia e regulamenta a profissão de Psicologista). Diário Oficial da União.

Nascimento, A. B., Campos, C. M., \& Alt, F. (2012). Psicologia fenomenológica, psicanálise existencial e possibilidades clínicas a partir de Sartre. Estudos e Pesquisas em Psicologia, 12(3), 706723.

Oliveira, I. T. (1999). Psicoterapia psicodinâmica breve: Dos precursores aos modelos atuais. Psicologia: Teoria e Prática, 1(2), 919.

Pires, A. C. T., \& Braga, T. M. S. (2009). O psicólogo na saúde pública: Formação e inserção profissional. Temas em Psicologia, 17(1), 151-162.

Poubel, P. F. (2014). Psicologia na saúde pública. Estudos Contemporâneos da Subjetividade, 4(2), 193200.

Pretto, Z., Langaro, F., \& Santos, G. B. (2009). Psicologia clínica existencialista na atenção básica à saúde: Um relato de atuação. Psicologia: Ciência e Profissão, 29(2), 394-405. https://doi.org/10.1590/S1414-98932009000200014

Sartre, J.-P. (2002). Crítica da razão dialética: Precedido por questões de método. DP\&A. (Trabalho original publicado em 1960).

Sartre, J.-P. (2011). O Ser e o nada: Ensaio de ontologia fenomenológica (19a ed.). Vozes. (Trabalho original publicado em 1943).

Scarparo, H. B. K., \& Guareschi, N. M. F. (2007). Psicologia social comunitária profissional. Psicologia \& Sociedade, 19(spe2), 100108. http://doi.org/10.1590/S0102-71822007000500025

Schneider, D. R. (2002). Novas perspectivas para a psicologia clínica: Um estudo a partir da obra de "Saint-Genet: Comédien et martyr" de Jean-Paul Sartre [Tese de doutorado, Pontifícia Universidade Católica de São Paulo]. UFSC Psiclin. http://www.psiclin.ufsc.br/files/2010/05/Tese.pdf

Schneider, D. R. (2006). Liberdade e dinâmica psicológica em Sartre. Natureza Humana, 8(1), 283314.

Spink, M. J. P. (2011). Psicologia social e saúde: Práticas, saberes e sentidos (8a ed.). Vozes.

Tassinari, M. (2009). Plantão psicológico como promoção de saúde. In A. Bacellar (Ed.), A psicologia humanista na prática: Reflexões sobre a abordagem centrada na pessoa (pp. 172-189). Editora da Unisul.

Vaccaro, M. M. (2014). Constituição do sujeito e historicidade: Um estudo a partir do existencialismo sartreano [Dissertação de mestrado, Universidade Estadual de Maringá]. Repositório Institucional da UEM. http:// repositorio.uem.br:8080/jspui/handle/1/3027 
Vendruscolo, J. (2015). Atendimento psicológico em instituições: Da tradição à fenomenologia-existencial. In P. E. R. A. Evangelista (Org.), Psicologia fenomenológico-existencial: Possibilidades da atitude clínica fenomenológica (2a ed., pp. 119139). Via Verita.

\section{Franciele Cabral Leão-Machado}

Mestre em Psicologia pela Universidade Estadual de Maringá (UEM), Maringá - PR. Brasil.

E-mail: psifrancieleleao@gmail.com

(D) https://orcid.org/0000-0001-6046-6484

\section{Marina Menegueti Vaccaro}

Doutoranda em Psicologia pela UEM, Maringá - PR. Brasil.

E-mail: marinamenegueti@gmail.com

(D) https://orcid.org/0000-0002-8286-7550

\section{Sylvia Mara Pires de Freitas}

Doutora em Psicologia pela UEM, Maringá - PR. Brasil.

E-mail: sylviamara@gmail.com

(iD http://orcid.org/0000-0002-5882-7065

Endereço para envio de correspondência:

Universidade Estadual de Maringá. Av. Colombo, 5790, bloco 118, Zona 7. CEP: 87020-900. Maringá - PR. Brasil.

Recebido $13 / 08 / 2018$

Aceito 06/04/2020

Received $08 / 13 / 2018$

Approved 04/06/2020

Recibido $13 / 08 / 2018$

Aceptado 06/04/2020

Como citar: Machado, F. C. L., Vaccaro, M. M., \& Freitas, S. M. P. (2021). Atendimentos psicológicos breves em instituições públicas de saúde: Contribuições do existencialismo sartriano. Psicologia: Ciência e Profissão, 41 (n.spe 4), 1-12. https://doi.org/10.1590/1982-3703003211479

How to cite: Machado, F. C. L., Vaccaro, M. M., \& Freitas, S. M. P. (2021). Brief psychological therapy sessions in public health institutions: Contributions of the sartrean existentialism. Psicologia: Ciência e Profissão, 41 (n.spe 4), 1-12. https://doi.org/10.1590/1982-3703003211479

Cómo citar: Machado, F. C. L., Vaccaro, M. M., \& Freitas, S. M. P. (2021). Atención psicológica breve en instituciones públicas sanitarias: Contribuciones del existencialismo sartriano. Psicologia: Ciência e Profissão, 41 (n.spe 4), 1-12. https://doi.org/10.1590/1982-3703003211479 